Nevşehir Bilim ve Teknoloji Dergisi (2019), 8(IMSMATEC Özel Sayı) 21-28

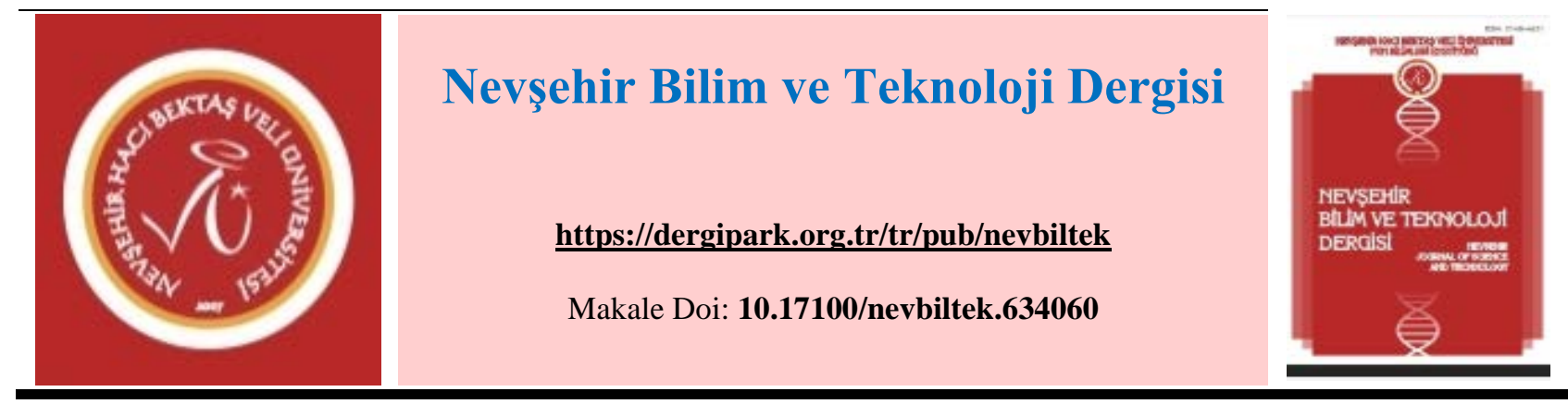

\title{
AISiCu (LM24) Alüminyum Alaşımında Modifikasyon Ve Tane İnceltmenin Mikroyapı Ve Mekanik Özelliklere Etkisi
}

\author{
Tansel TUNÇAY ${ }^{1}$ \\ ${ }^{1}$ Karabük Üniversitesi, Teknoloji Fakültesi, Imalat Mühendisliği Bölümü, Karabük \\ ORCID ID: 0000-0002-7762-8504
}

Öz

$\mathrm{Bu}$ çalışmada, AlSiCu alaşımına Stronyum (Sr) ile modifikasyon ve Al5TiB ile tane inceltme işlemi uygulanmıştır. Çalışmada AlSiCu alaşımı yaklaşı 150-200 ppm Sr ile modifikasyon ve \%0,75 ve 1,5 Al5TiB ile tane inceltme işlemi uygulandıktan sonra metal ve kum kalıba döküm metodu ile üretilmiştir. Mikroyapı incelemeleri optik mikroskop (OM), tarama elektron mikroskobu (SEM/EDS analizi), mekanik özelikler; çekme testi ve sertlik ölçümleri ile değerlendirildi. Sonuç olarak; optik mikroskop (OM) incelemelerinde metal kalıba dökülen AlSiCu alaşımında Al-Si ötektiğinin daha homojen ve ince dağıldığı belirlendi. Sr modifikasyonu ile Al-Si ötektiğinin morfolojisinin değiştirdiği görülmüştür. Al5TiB ilavesi ile yapının özellikle metal kalıba dökülen alaşımda dendritlerin daha düzenli olduğu fakat boşluk miktarının arttığı görülmektedir. Tarama elektron mikroskobu (SEM) görüntülerinde kum kalıba ve metal kalıba dökülen A15TiB ile tane inceltme işlemi uygulanmış alaşımda Al2Cu fazının kum kalıba dökülen alaşım sisteminde daha fazla olduğu belirlenmiştir.

Anahtar Kelimeler: Al-Si-Cu alaşımı, modifikasyon, tane inceltme, mikro yapı, mekanik özellikler.

\section{The Effect of Modification and Grain Refining on Microstructure and Mechanical Properties of AlSiCu (LM24) Aluminum Alloy}

\begin{abstract}
The modification process with Strontium (Sr) and grain refining process with Al5TiB were applied to AlSiCu alloy in this study. AlSiCu alloy was produced with metal mould and sand mould casting methods after applying modification process with approximately 150-200 ppm Sr and grain refining process with $0.75 \%$ and $1.5 \% \mathrm{Al}-5 \mathrm{TiB}$. Microstructure analyses were evaluated by optical microscope (OM) and scanning electron microscope (SEM / EDS analysis), and mechanical properties by tensile test and hardness measurements. As a result, Al-Si eutectic in AlSiCu alloy which was casted into metal mould was found to be more homogeneous and finely dispersed in accordance with optical microscope (OM) analyses. It was observed that the morphology of Al-Si eutectic changed by Sr modification. It was seen with the addition of Al5TiB that dendrites in structure were more regular in the alloy casted into metal mould and yet the amount of space increased. When it was examined the images of the scanning electron microscope (SEM) of the alloys which were casted into metal and sand moulds and to which grain refining process was applied, the Al2Cu phase was determined to be more in the alloy system casted into sand mould.
\end{abstract}

Keywords: Al-Si-Cu alloys, modification, grain refinement, microstructure, mechanical properties. 


\section{Giriş}

Al-Si-Cu alaşımları özellikle otomotiv endüstrisinde alaşımları hafiflikleri, yüksek dökülebilirlik ve mekanik özellikleri karakteristikleri nedeniyle tercih edilen alaşım sistemidir. Al-Si-Cu alaşım malzemeler özellikle motor bloklarında silindir başlarında kullanılmaktadır [1]. Bununla birlikte döküm metodu ile üretilen malzemelerin mekanik özellikleri, kimyasal kompozisyona, uygulanan ek prosese (gaz giderme, modifikasyon, tane inceltme vb.), kalıp malzemesine, döküm sıcaklığına ve katılaşmanın diğer önemli parametrelerine bağlıdır. Katılaşma sıcaklığı aralığı kimyasal kompozisyona bağılıır, ayrıca sıvı metale tane inceltici elemanların ilavesi ile çekirdeklenme sayısının artmasıyla mikroyapıyı oluşturan taneler inceltilmektedir [2]. Modifikasyon ile özellikle Al-Si ötektiğinin morfolojisinin değiştirilerek malzemenin sünekliğinde önemli ölçüde iyileşme sağlanmaktadır. Modifikasyon işleminde Na benzeri tuzlar ile birlikte, farklı oranlarda stronyum master alaşımları kullanılmaktadır. Al ve alaşımlarında genellikle bilinen en etkin ve kullanılan tane inceltici olarak, KBF4, K2TiF6 (tuz derişimli), AlTiB (farklı Ti:B oranına sahip), AlTi, AlTiC vb titanyum esaslı master alaşımlar, son yıllarda AlB,AlB3,NiB gibi bor içerikli master alaşımlar kullanılmaktadır. Al alaşımları; yarı katı ve sıvı halde iken, $\mathrm{TiB}_{2}$ ve $\mathrm{Ti}_{3} \mathrm{Al}$ partikülleri heterojen çekirdeklenme için uygun sit alanları oluşturmaktadır ve mikroyapının şekillendirilmesinde etkin rol oynamaktadır [3-4]. Rathi ve ark., $\mathrm{A} 17 \mathrm{Si} 3 \mathrm{Cu}$ alaşımına $\mathrm{A} 15 \mathrm{TiB}$ ile tane inceltme işlemi ve Al10Sr ile modifikasyon işlemi uygulamışlardır. Sonuç olarak

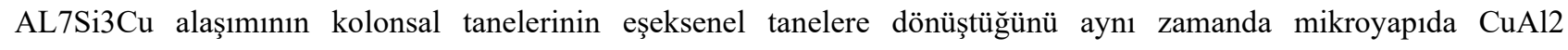
çökeltilerinin bulunduğunu belirlemişler. Alaşımının tane inceltme ve modifikasyonu ile sıcak yırtılmaya karşı direnç gösterdiğini not etmişlerdir [1]. D’Elia ve Ravindran, B206 ve A319 alaşımlarına A15TiB ile tane inceltme işlemi uygulamışlar ve permanenet kalıba dökerek sıcak yırtılma karakteristiğini değerlendirmişlerdir. Çalışmada alaşımların içerdiği Ti miktarının artması ile ortalama tane boyutunun azaldığını ve buna bağlı olarak sıcak yırtılma direncinin artığını belirlenmişlerdir. Ayrıca Ti-B ile yapılan tane inceltme işleminin B206 alaşımında A319 alaşımına göre daha iyi olduğunu bildirmişlerdir [5]. Timelli ve ark, AlSiCu alaşımlarına uygulanan tane inceltme işlemi ile Farklı Ti içeriği ve katılaşma oranına bağlı olarak çekme testi sonuçları Weibull istatiksel metodu ile değerlendirmişlerdir [6]. Wang ve ark., alüminyum 6063 alaşımında Al-Ti-C-B ile uygulanan tane inceltici limitlerini araştırmışlardır. \%1.5 tane incelticinin etkin olduğu daha sonra ise mekanik özellikleri olumsuz etkilediğini bildirmektedirler [7].

Bu çalışmada, LM24 alaşımları önce A15TiB master alaşımı ile de tane inceltme işlemi ardından Al10Sr ile modifikasyon işlemine tabi tutulmuştur. Daha sonra kum ve metal kalıba döküm metotları ile farklı soğuma ortamlarında katılaştırılmıştır. Mikroyapısal değişiklikler ve buna bağlı olarak mekanik test sonuçları ile uygulanan tane inceltme ve modifikasyon işleminin alaşım üzerine etkisinin belirlenmesi amaçlanmıştır. .

\section{Materyal ve Metot}

Çalışmada kullanılan LM24 (Al-Si-Cu) alaşımı, modifikasyon (A110Sr) ve tane inceltme (A15TiB) master alaşımlarının kimyasal bileşimleri, Tablo 1'de verilmiştir.

Tablo 1. Çalışmada kullanılan LM24, Al15Sr modifikasyon ve A15TiB master alaşımı kimyasal bileşimi (A ğ.\%)

\begin{tabular}{cccccccccc} 
& Si & Mg & Fe & Cu & Mn & Ti & B & Sr & Al \\
\hline LM24 & 8,05 & 0,24 & 0,14 & 3,4 & 0,12 & 0,7 & --- & -- & Kalan \\
Al15Sr & --- & --- & --- & --- & --- & --- & -- & 14,9 & Kalan \\
Al5TiB & --- & --- & --- & --- & --- & 5,1 & 1 & -- & Kalan \\
\hline
\end{tabular}

Çalışmadaki her grup tek başına ergitme işlemi ile üretildi. LM24 alaşımı 4kW gücündeki elektrik direnç ocağında paslanmaz çelik pota içinde ergitildi. Pota yüzeyi BN ile kaplandı. Ergiyik alaşıma Al10 Sr $(0,020 \mathrm{Sr} \%$ ağ.) 
Nevşehir Bilim ve Teknoloji Dergisi (2019), 8(IMSMATEC Özel Sayı) 21-28

ilave edilerek 5 dakika bekletildikten sonra, Al5TiB tane inceltme elemanı (0,75 ve 1,5 Al5TiB \% ăg.) ilave edildi. Tane inceltme işleminden sonra hazırlanan sıvı metal homojen karışım sağlamak için $5 \mathrm{dk}$ beklenildi. Sıvı metal yaklaşık $680-720^{\circ} \mathrm{C}^{\prime}$ da hazırlanan kum ve metal kalıplara dökülmüştür. Kum kalıpların yapımında, 60-70 AFS silis kumu, reçine ve serter ile karıştırılarak hazırlanan kum kalıbın (Şekil 1.a) ve ST52 kalite çelikten hazırlanan metal kalıbın görüntüsü (Şekil 1.b) verilmiştir. Metal kalıpların yüzeyine sıvı metalin yapışmasını engellemek için BN sprey boya ile boyandi.
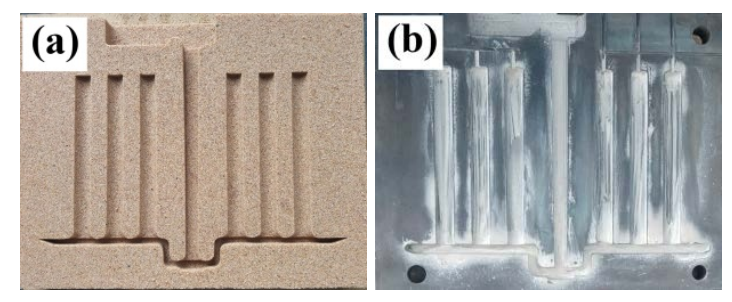

Şekil 1. Kum kalıbın (a) ve metal kalıbın görüntüsü (b)

Modifikasyon ve tane inceltme işlemi uygulanan LM 24 alaşımlara, yapay yaşlandırma (T6) 1sıl işlemi yapılmıştır. T6 1 sıl işleminde alaşımlar, $515{ }^{\circ} \mathrm{C}^{\prime}$ de 8 saat solüsyona alındıktan sonra suda soğutulmuştur. Oda sıcaklığında 24 saat doğal yaşlandırıldıktan sonra, $170^{\circ} \mathrm{C}^{\prime}$ de 10 saat yapay yaşlandırılmıştır.

Metalografik numuneler ASTM E03-11 standardına göre hazırlandı. Standart metalografik işlemlerle hazırlanan numuneler, Keller solüsyonu (2 ml HF (\%48) + $3 \mathrm{ml} \mathrm{HCl}+5 \mathrm{ml} \mathrm{HNO}_{3}+190 \mathrm{ml} \mathrm{H}_{2} \mathrm{O}$ ) ile 30-45 s. dağlandı. Optik mikroskop incelemeleri, NIKOL marka optik mikroskop, Tarama elektron mikroskobu (SEM) ve enerji dağılım spektrometresi (EDS) incelemeleri, Carl Zeiss Ultra Plus Gemini (FEG) marka taramalı elektron mikroskobunda yapıldı. Kum ve permanent kalıba döküm metodu ile üretilen LM24 alaşımlarından ASTM B557M-10 standardına uygun 6 adet çekme numunesi hazırlanmıştır. Çekme test numunesinin ölçüleri Şekil 2'de verilmiştir. Çekme testleri, 50 kN kapasiteli SHIMADZU AG-IS model çekme cihazında ve 1 mm/dak çekme hızında test edildi.

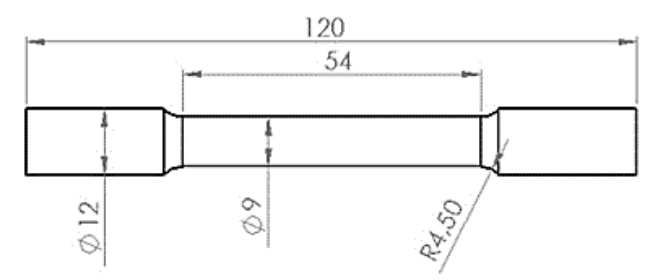

Şekil 2. Çalışmada test edilen çekme testi numunelerin ölçüleri

Alaşımların sertlik testleri AFFRI marka VRSD251 model sertlik ölçme cihazında $2.5 \mathrm{~mm}$ bilye çapında 31.25 kgf yük altında sertlik değerleri ölçülmüştür. Sertlik sonuçları 5 ölçümün ortalaması alınarak belirlendi.

\section{Sonuçlar ve Tartışma}

\subsection{Mikroyapı Íncelemeleri}

Çalı̧̧mada döküm metodu ile modifikasyon ve tane inceltme işlemi uygulanmış LM 24 alaşımların kimyasal bileşimleri Tablo 2'de verilmişsir. 
Nevşehir Bilim ve Teknoloji Dergisi (2019), 8(IMSMATEC Özel Sayı) 21-28

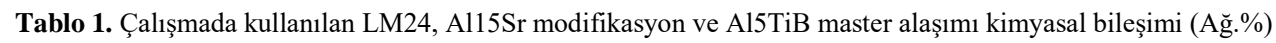

\begin{tabular}{lccccccccc}
\hline & $\mathbf{S i}$ & $\mathbf{M g}$ & $\mathbf{F e}$ & $\mathbf{C u}$ & $\mathbf{M n}$ & $\mathbf{T}$ & $\mathbf{B}$ & $\mathbf{S r}$ & $\mathbf{A l}$ \\
\hline $\mathbf{L M 2 4}$ & 7.88 & 0.002 & 0.13 & 3.68 & 0.002 & 0.006 & - & - & Kalan \\
$\mathbf{L}$ & & & & & & & & & \\
LM24+Sr & 7.82 & 0.002 & 0.12 & 3.56 & 0.002 & 0.006 & - & 0.018 & Kalan \\
LM24+Sr+0,75Al5TiB & 7.99 & 0.002 & 0.14 & 3.81 & 0.002 & 0.046 & - & 0.018 & Kalan \\
& & & & & & & & & \\
LM24+Sr+1,50Al5TiB & 8.01 & 0.002 & 0.14 & 3.80 & 0.002 & 0.079 & - & 0.016 & Kalan \\
\hline
\end{tabular}

Modifikasyon ve tane inceltme işlemi uygulanmış LM 24 alaşımların optik mikroskop (OM) ve tarama elektron mikroskobu (SEM) görüntüleri, Şekil 3' de verilmiştir.

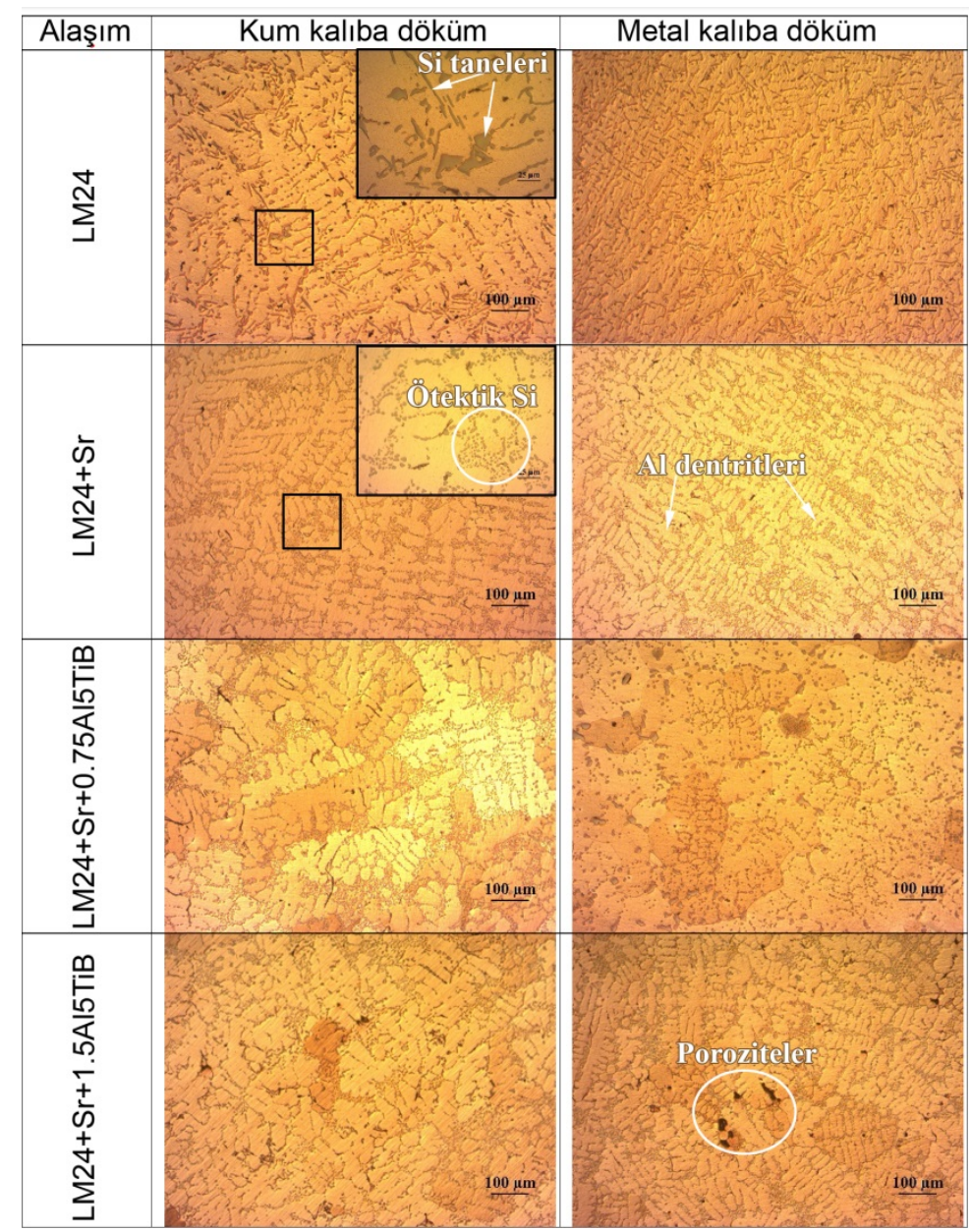

Şekil 3. Modifikasyon ve tane inceltme işlemi uygulanmış LM24 alaşımların optik mikroskop (OM) görüntüleri

Döküm sonrasında alınan kimyasal sonuçlar incelendiğinde, alaşımların içerdiği tane inceltici master alaşım miktarı artmasına bağlı olarak Ti miktarının artı̆̆ı görülmektedir. LM24 alaşımların farklı kalıplar içinde soğuması sonucunda elde edilen optik mikroskop görüntülerinde, modifikasyon ile yapıdaki Al-Si ötektiğinin yapısal dönüşümü görülmektedir. Ayrıca soğuma hızına bağlı olarak metal kalıplarda daha ince tane yapısına sahip olduğu belirlenmiş̧ir. Bununla birlikte özellikle metal kalıplara dökülen alaşımlarda al- dendritlerin daha düzenli ve kolonsal morfolojide olduğu görülmektedir. Dendrit kollar arasında porozitenin varlığı göze çarpmaktadır. Timelli ve ark., yaptıkları çalışmada AlSi7Cu3Mg alaşımı için tane inceltme işleminde A15TiB master alaşımının net bir şekilde al- dendritlerin yapısında bir değişime sebep olmadığını belirmektedir. Fakat soğuma oranı ve az miktarda kullanılan master alaşımın etkin olduğunu not etmiştir [6]. Çekirdeklenme için uygun alanların oluşması için ilave edilen Ti-B bileşik formları sıvı 
metal içinde birbirinden bağımsız alanlarda katılaşmaya sebep olmasından dolayı boşluk oluşumunu artışı olabileceği görülmektedir. LM24 alaşımın Stronyum ile modifikasyon ve \%0.75 A15TiB tane inceltme işlemi uygulanmış LM 24 alaşımın kum kalıba (a) ve metal kalıba (b) dökülmüş numunelerin SEM görüntüleri ve EDS analizleri Şekil 4 ve Tablo 3'te verilmiştir.
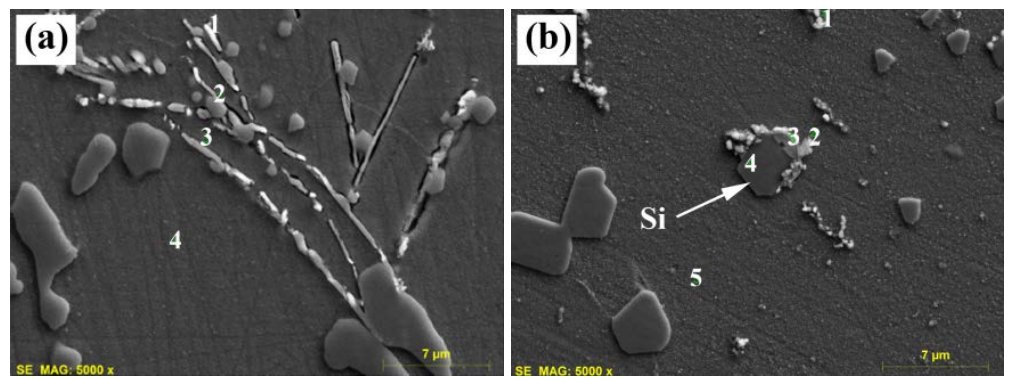

Şekil4. Stronyum ile modifikasyon ve \%0.75 Al5TiB tane inceltme işlemi uygulanmış LM 24 alaşımın kum kalıba (a) ve metal kalıba (b) dökülmüş numunelerin SEM görüntüleri.

Tablo 3. Stronyum ile modifkasyon ve \%0.75 Al5TiB tane inceltme işlemi uygulanmış LM 24 alaşımın kum kalıba ve metal kalıba dökülmüş numunelerin EDS analizi sonuçları.

\begin{tabular}{|c|c|c|c|c|c|c|c|c|}
\hline \multirow{2}{*}{\multicolumn{2}{|c|}{ Konum }} & \multicolumn{7}{|c|}{ Elementler (\% A } \\
\hline & & \multirow{2}{*}{$\frac{\mathrm{Al}}{\mathrm{C} 30.91}$} & \multirow{2}{*}{$\begin{array}{c}\mathrm{Si} \\
1.15\end{array}$} & \multirow{2}{*}{$\begin{array}{c}\mathrm{Cu} \\
45.27\end{array}$} & \multirow{2}{*}{$\begin{array}{c}\mathrm{Fe} \\
1.53\end{array}$} & \multirow{2}{*}{$\begin{array}{c}\mathrm{Ti} \\
-\end{array}$} & \multirow{2}{*}{$\begin{array}{c}\mathrm{B} \\
11.70\end{array}$} & \multirow{2}{*}{$\frac{\mathrm{O}}{9.45}$} \\
\hline \multirow{3}{*}{$\frac{\tilde{d}}{\dot{+}}$} & 1 & & & & & & & \\
\hline & 2 & 24.15 & 52.06 & 4.26 & 0.71 & - & 16.44 & 2.38 \\
\hline & 3 & 38.48 & 0.67 & 40.99 & 2.03 & - & 12.80 & 5.03 \\
\hline \multirow{4}{*}{ 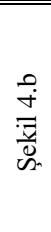 } & 1 & 57.67 & 1.48 & 9.64 & - & 0.21 & 0 & 30.99 \\
\hline & 2 & 47.67 & 1.64 & 9.38 & 3.56 & - & 14.59 & 23.16 \\
\hline & 3 & 21.58 & 25.02 & 41.14 & 2.47 & - & 7.01 & 2.77 \\
\hline & 4 & 1.92 & 85.89 & 0.71 & 0 & - & 10.30 & 1.17 \\
\hline
\end{tabular}

Şekil 4'teki SEM ve EDS analizi sonuçları incelendiğinde, Al matris içinde küresel şekilli Si taneleri görülmektedir. Ayrıca özellikle Si taneleri arasında bileşimde çok düşük miktarda Fe olmasına rağmen yapıda oluşan Fe-bazlı intermetaliklere yakın bölgelerde uygulanan yaşlanma 1sıl işlemi ile oluşan A12Cu çökeltilerinin dizildiği görülmektedir. Sr ile modifikasyon Si tanelerinin keskin köşelerinin ortadan kalktığı ve mekanik özelliklerin iyileştiği bilinmektedir. Fe-bazlı intermetalikler genellikle alaşımın mekanik özelliklerini olumsuz olarak etkilediği birçok çalışmada belirtilmiştir. LM24 alaşımının Stronyum ile modifikasyon ve \% 1.50 Al5TiB tane inceltme işlemi uygulanmış alaşımının kum kalıba (a) ve metal kalıba (b) dökülmüş numunelerin SEM görüntüleri Şekil 5’te verilmiştir.
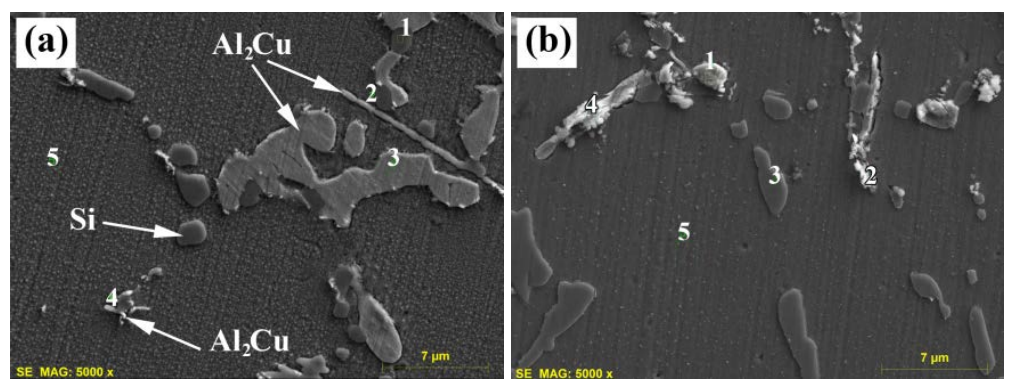

Şekil 5. Stronyum ile modifikasyon ve \%1.50 Al5TiB tane inceltme işlemi uygulanmış LM 24 alaşımın kum kalıba (a) ve metal kalıba (b) dökülmüş numunelerin SEM görüntüleri. 
Nevşehir Bilim ve Teknoloji Dergisi (2019), 8(IMSMATEC Özel Sayı) 21-28

Tablo 4. Stronyum ile modifkasyon ve $\% 1.50 \mathrm{Al}$ TiB tane inceltme işlemi uygulanmış LM 24 alaşımın kum kalıba ve metal kalıba dökülmüş numunelerin EDS analizi sonuçları.

\begin{tabular}{|c|c|c|c|c|c|c|c|c|}
\hline \multirow{2}{*}{\multicolumn{2}{|c|}{ Konum }} & \multicolumn{7}{|c|}{ Elementler (\% A ‘̆.) } \\
\hline & & $\mathrm{Al}$ & Si & $\mathrm{Cu}$ & $\mathrm{Fe}$ & $\mathrm{Ti}$ & B & $\mathrm{O}$ \\
\hline \multirow{5}{*}{ 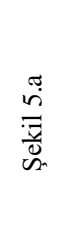 } & 1 & 1.16 & 87.06 & 0.01 & - & - & 10.97 & 0.80 \\
\hline & 2 & 28.37 & 2.37 & 46.57 & 2.96 & - & 8.77 & 10.97 \\
\hline & 3 & 32.05 & 0.48 & 55.94 & 0.86 & 0.82 & 6.17 & 3.67 \\
\hline & 4 & 30.95 & 0.74 & 49.35 & 1.38 & - & 9.17 & 7.91 \\
\hline & 5 & 79.62 & 0.65 & 6.89 & - & - & 11.24 & 1.59 \\
\hline \multirow{5}{*}{ 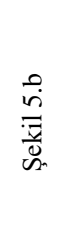 } & 1 & 14.99 & 0.30 & 59.37 & 0.52 & 0.08 & 1.71 & 23.02 \\
\hline & 2 & 47.85 & 1.14 & 10.08 & 5.05 & 0.73 & 14.20 & 20.95 \\
\hline & 3 & 3.81 & 84.71 & 0.72 & 0.12 & - & 9.76 & 0.87 \\
\hline & 4 & 35.68 & 0.41 & 30.75 & - & - & 0.04 & 33.12 \\
\hline & 5 & 89.92 & 0.76 & 6.62 & - & - & - & 1.90 \\
\hline
\end{tabular}

Kum kalıba dökülen LM24 alaşımının, A15TiB master alaşım ilavesinin artması ile mikroyapıda oluşan Si tanelerinin küçüldüğü ve $\mathrm{A} 2 \mathrm{Cu}$ çökeltilerinin hacimsel olarak şekillerinin büyüdüğü belirlenmiştir. Metal kalıpta ise daha ince ve ağ şeklinde $\mathrm{A} 2 \mathrm{Cu}$ çökeltilerinin oluştuğu görülmektedir. Si taneleri hemen hemen aynı boyutlardadır. Isıl işlem ile oluşan bu çökelti fazın oluşumunu artırdığı düşünülmektedir. Genel olarak $\mathrm{Al} 2 \mathrm{Cu}$ çökelti fazının, kum kalıpta soğuyan alaşımların mikroyapılarında ince ve Al-matris içinde oluştuğu görülürken, metal kalıpta soğuyan alaşımlarda özellikle Si taneleri çevresinde kümeleştiği belirlenmiştir.

\subsection{Mekanik Özellikler}

Bu çalışmada elde edilen Sr ile modifikasyon ve A15TiB ile tane inceltme işlemi uygulanmış LM 24 alaşımların makro sertlik ve çekme test sonuçları, Tablo 5'te verilmiştir. Makro sertlik ölçümlerinde, üç farklı numunenin her birinden 5 adet ölçümün ortalaması alınarak hesaplanmıştır. Çekme test sonuçlarında elde edilen 6 çekme test numunesinden elde edilen maksimum çekme mukavemeti (UTS) ve yüzde uzama (\%e) değerlerinin ortalaması alınmıştır.

Tablo 5. Modifikasyon ve tane inceltme işlemi uygulanmıș LM24 alaşımların makro sertlik, çekme testi sonuçları

\begin{tabular}{|c|c|c|c|c|c|c|}
\hline \multirow{3}{*}{ Alaşımlar } & \multicolumn{2}{|c|}{ Makrosertlik Ortalamaları } & \multicolumn{4}{|c|}{ Çekme Test Sonuçları Ortalamaları } \\
\hline & \multirow[t]{2}{*}{ Kum kalıp } & \multirow[t]{2}{*}{ Metal kalıp } & \multicolumn{2}{|c|}{ Kum kalıp } & \multicolumn{2}{|c|}{ Metal kalıp } \\
\hline & & & UTS & $\mathrm{E} \%$ & UTS & $\mathrm{E} \%$ \\
\hline LM24 & 108.00 & 108.80 & 226 & 8.6 & 250 & 9.5 \\
\hline LM24+Sr & 74.63 & 101.93 & 196 & 9,50 & 246 & 10.4 \\
\hline LM24+Sr+0.75Al5TiB & 80.37 & 102.77 & 209 & 10 & 270 & 12.2 \\
\hline LM24+Sr+1.50Al5TiB & 75.60 & 102.33 & 199 & 9.45 & 250 & 13.9 \\
\hline
\end{tabular}

LM24 alaşımı kum ve metal kalıba döküm sonrasında alaşımın makro sertlik değerlerinde dikkate değer bir fark görülmemektedir. Ayrıca $\mathrm{Sr}$ modifikasyonu ve tane inceltme işlemi ile üretilen alaşımların makro sertlik değerlerinin düştüğü görülmektedir. Bu düşüşün modifikasyon işlemi sırasında Al-Si ötektiğinin morfolojisindeki değişimi ile ilgili olduğu düşünülmektedir. Plaka şeklindeki Al-Si ötektiği küresel şekline dönüşmesi yapıda baskın olan fazın dolayısı ile alaşımların sertliklerinde etkin rol oynamıştır. Optik mikroskop görüntülerinde (Şekil 2.) Al-Si ötektiğinin çıtalı morfolojisinden daha küresel ve küresele yakın şekilde olduğu görülmektedir. Kalıp malzemesine göre modifikasyon ve tane inceltme işleminin makro sertlik üzerine etkisi olduğu anlaşılmıştır. Çekme test sonuçları maksimum dayanım ve yüzde uzama değerleri üzerinden değerlendirildiğinde modifikasyon ve tane inceltme işleminin 
Nevşehir Bilim ve Teknoloji Dergisi (2019), 8(IMSMATEC Özel Sayı) 21-28

yüzde uzama değerini net olarak artırdığı görülmektedir. Makro sertlik ve yüzde uzama değerleri birbirini desteklemektedir. Çekme testinde elde edilen bu süneklikteki artış sertlik değerlerinde düşme olarak karşımıza çıkmaktadır.

\section{Sonuçlar}

LM24 alaşımının Sr ile modifikasyon ve Al5TiB ile tane inceltme işlemi uygulanan alaşımlarının mikro yapı incelemeleri ve mekanik özellikleri incelenmiş ve elde edilen sonuçlar aşağıda sıralanmıştır.

> LM24 alaşımına Sr ilavesi ile Al-Si ötektiğinin morfolojik yapısı keskin köşeli plakalı formundan küresel şekle dönüşmektedir. (Şekil 2, OM görüntüleri)

$>$ Sr ilavesi ile kum ve metal kalıpta katılaştırılan alaşımın sertliği, çekme mukavemeti düşmektedir. Fakat tane inceltme ile alaşımın süneklik değeri iyileştirilmiştir.

> LM24 alaşımına ilave edilen Sr modifikasyonu kalıp malzemesine bağlı olmaksızın alaşımın makro sertliği üzerine etkisi görülmemiştir. Tane inceltici ilavesi ile makro sertlik değerinde azalmalar olduğu belirlenmiştir.

> Tane inceltme işlemi ile alaşımın maksimum çekme mukavemeti ve yüzde uzama miktarı artmaktadır. Özellikle en yüksek çekme mukavemeti 0.75 Al5TiB tane inceltici ilavesi ile ve en yüksek yüzde uzama ise \%1.5 Al5TiB tane inceltici ilavesi ile elde edilmiştir. (Tablo 5)

> Kum kalıba dökülen alaşımların mekanik özelliklerinin metal kalıba dökülen alaşımlardan düşük olduğu belirlenmiştir.

\section{Kaynaklar}

[1] Rathi, S.K., Sharma, A., Di Sabatino A., "Effect of mould temperature, grain refinement and modification on hot tearing test in Al-7Si-3Cu alloy” Engineering Failure Analysis, 79, 592-605, 2017.

[2] Campbell, J., “Complete Casting Handbook Metal Casting Processes”, Metallurgy, Techniques and Design, Oxford, 2010.

[3] Birol, Y., "An improved practice to manufacture Al-Ti-B master alloys by reacting halide salts with molten aluminium” Journal of Alloys and Compounds, 420, 71-76, 2006.

[4] Birol, Y., "A novel Al-Ti-B alloy for grain refining Al-Si foundry alloys", Journal of Alloys and Compounds, 486 219-222, 2009.

[5] D’Elia, F., Ravindran, C., "Influence of grain refinement on hot tearing in B206 and A319 aluminum alloys”, Transactions of The Indian Institute of Metals, 62, 315-319, 2009.

[6] Timelli, G., Camicia, G., Ferraro S., "Effect of grain refinement and cooling rate on the microstructure and mechanical properties of secondary Al-Si-Cu alloys”, Journal of Materials Engineering and Performance, 611-621, 2014.

[7] Wang, E., Gao, T., Nie, J., Liu. X., “Grain refinement limit and mechanical properties of 6063 alloy inoculated by Al-Ti-C (B) master alloys”, Journal of Alloys and Compounds, 594, 7-11, 2014. 
Nevşehir Bilim ve Teknoloji Dergisi (2019), 8(IMSMATEC Özel Sayı) 21-28

\section{Extended Abstract}

\section{Introduction}

Al-Si-Cu alloys are preferred alloy system especially in automotive industry because of their lightness, high castability and mechanical properties. Al-Si-Cu alloy materials are used in cylinder heads especially in engine blocks. However, the mechanical properties of the materials produced by the casting method depend on the chemical composition, the additional process applied (degassing, modification, grain refining, etc.), the moulding material, the casting temperature and other important parameters of solidification. The solidification temperature range depends on the chemical composition, and the addition of grain refinement elements to the liquid metal increases the number of nucleation and the particles forming the microstructure are refined. The modification significantly improves the ductility of the material, in particular by modifying the morphology of the Al-Si eutectic.

In this study, LM24 alloys were first subjected to grain refining with Al5TiB master alloy and then modified with Al10Sr. Then, it was solidified in different cooling environments by sand and metal casting methods. It is aimed to determine the effect of microstructural changes and consequently mechanical test results and grain refining and modification process on the alloy. Microstructure analyses were evaluated by optical microscope (OM) and scanning electron microscope (SEM / EDS analysis), and mechanical properties by tensile test and hardness measurements.

\section{Method}

In this study, the modification process with Strontium (Sr) and grain refining process with Al5TiB were applied to AlSiCu alloy in this study. AlSiCu alloy was produced with metal mould (St 52 steel) and sand mould casting methods after applying modification process with approximately 150-200 ppm Sr and grain refining process with $0.75 \%$ and $1.5 \%$ Al-5TiB.

\section{Results and Discussion}

As a result, Al-Si eutectic in AlSiCu alloy which was casted into metal mould was found to be more homogeneous and finely dispersed in accordance with optical microscope (OM) analyses. It was observed that the morphology of Al-Si eutectic changed by Sr modification. It was seen with the addition of Al5TiB that dendrites in structure were more regular in the alloy casted into metal mould and yet the amount of space increased. When it was examined the images of the scanning electron microscope (SEM) of the alloys which were casted into metal and sand moulds and to which grain refining process was applied, the $\mathrm{Al} 2 \mathrm{Cu}$ phase was determined to be more in the alloy system casted into sand mould. Modification with Sr to the LM 24 alloy, the morphological structure of the Al-Si eutectic changes from a sharp-edged plate form to a spherical shape. Modification with Sr, the hardness and tensile strength of the alloy solidified in sand mould and metal mould decreases. However, the ductility value of the alloy was improved by grain refinement. LM24 alloy had no effect on the macro hardness of the alloy regardless of the mould material. Decrease in macro hardness was determined with the addition of grain refinement. The maximum tensile strength and percentage elongation of the alloy increases with grain refining. In particular, the highest tensile strength was obtained by the addition of $0.75 \mathrm{Al} 5 \mathrm{TiB}$ grain refinement and the highest percent elongation was achieved by the addition of $1.5 \%$ Al5TiB grain refinement. 